\title{
Effects of ventilation, humidity and temperature on airway responsiveness to methacholine in rats
}

\author{
F.M. Arantes-Costa, S. Zoriki, M.H.C. Santos, C.H.P. Kobata, J.E. Vieira, M.A. Martins
}

Effects of ventilation, humidity and temperature on airway responsiveness to methacholine in rats. F.M. Arantes-Costa, S. Zoriki, M.H.C. Santos, C.H.P. Kobata, J.E. Vieira, M.A. Martins. C ERS Journals Ltd 2002.

ABSTRACT: Exercise-induced bronchoconstriction is associated with heat and water loss from the airways. It is not known whether these conditions can influence the response to bronchoactive agonists. The effects of different degrees of alveolar ventilation on the pulmonary response to methacholine and the role of humidity and temperature in this response were evaluated.

Wistar rats were anaesthetized, tracheostomized and mechanically ventilated. Increasing doses of methacholine were infused intravenously and respiratory system resistance $(R \mathrm{rs})$ and elastance $(E \mathrm{rs})$ were measured. The rats were ventilated with dry air at $13{ }^{\circ} \mathrm{C}$, dry air at $37^{\circ} \mathrm{C}$, humid air at $13{ }^{\circ} \mathrm{C}$ and humid air at $37^{\circ} \mathrm{C}$. These four groups were further divided into three subgroups with a respiratory frequency adjusted to reach a carbon dioxide tension in arterial blood of 30,40 and $50 \mathrm{mmHg}$.

Temperature, humidity and level of alveolar ventilation did not influence the position of the dose/response curve to methacholine. However, the maximal changes in $E_{\text {rs }}$ were significantly lower in the rats ventilated with humid air. In addition, maximal changes in $E$ rs were significantly higher in the rats with lower alveolar ventilation. These differences were not observed for maximal values of $R$ rs.

The pulmonary response to methacholine in normal rats is significantly affected by the humidity of inspired air and the level of alveolar ventilation. This influence is more intense in the small airways and/or distal airspaces. This suggests that exercise or hyperventilation can change the behaviour of airway smooth muscle.

Eur Respir J 2002; 19: 1008-1014.

Many inflammatory mediators, neurotransmitters and drugs can induce contraction of airway smooth muscle (ASM). The role of ASM in normal respiration is still the subject of debate, but it is unlikely that baseline airway tone is physiologically important, since bronchodilation induced by muscarinic antagonists or $\beta_{2}$-agonists does not appear to have adverse effects on airway function [1]. Most of the interest in ASM response to contractile agonists lies in the role of ASM in airway diseases, particularly asthma.

Airway hyperresponsiveness to nonspecific stimuli, such as methacholine, histamine, cold air or exercise, is an important feature of asthma. Airway hyperresponsiveness has been defined as an exaggerated response of the airways to nonspecific stimuli, resulting in airway obstruction, mainly due to excessive ASM contraction [2].

ASM can be constricted directly by agonists, such as methacholine or histamine, which activate receptors on the smooth-muscle cells, or by indirect mechanisms, such as cold air or exercise, which, at least in part, induce the release of bronchoactive mediators from mast cells $[1,2]$.
Dept of Medicine, School of Medicine, University of Sao Paulo, Sao Paulo, Brazil.

Correspondence: M.A. Martins, Departamento de Clínica Médica, Faculdade de Medicina da Universidade de São Paulo, Av. Dr. Arnaldo 455 Sala 1216, 01246-903 - São Paulo, SP, Brazil.

Fax: 551130850992

E-mail: mmartins@usp.br

Keywords: Airway smooth muscle, alveolar ventilation, experimental asthma, hyperventilation-induced bronchospasm, pulmonary responsiveness

Received: March 292001

Accepted after revision January 16 2002

This study was supported by the following Brazilian Scientific Agencies: Conselho Nacional de Desenvolvimento Científico e Tecnológico (CNPq), Fundação de Amparo à Pesquisa do Estado de São Paulo (FAPESP) and Programa de Núcleos de Excelência (PRONEX-MCT).
Exercise and hyperventilation result in similar transient increases in airway resistance in patients with asthma. It is generally accepted that the pathogenesis of exercise-induced bronchoconstriction (EIB) in asthma is associated with the fluxes of heat and water that develop in the airways during the warming and humidification of large volumes of air. The loss of both heat and water play a pivotal role in EIB and bronchospasm induced by hyperventilation. In addition, the inspiration of low-temperature air and dry air result in an increased prevalence of EIB compared to warm and humid air [3-5]. However, the relative effects of the degrees of ventilation, humidity and temperature on the pulmonary responsiveness to a bronchoactive agonist has not yet been studied. The authors reasoned that this kind of study could add relevant information to understanding of airway hyperresponsiveness and exerciseinduced bronchospasm.

Therefore, the aims of the present study were: 1) to study the effects of different degrees of alveolar ventilation on the pulmonary response to methacholine; and 2) to evaluate the effects of dry and humid 
air and of different temperatures of inspired air on these responses.

\section{Materials and methods}

\section{Study animals}

Male Wistar rats (250-350 g), obtained from the School of Medicine of the University of Sao Paulo (Sao Paulo, Brazil) were used. The rats were housed in conditions of a constant temperature and relative humidity and were fed a standard rat diet. Animals were kept free from all evidence of infectious diseases. All animals received humane care in compliance with the Helsinki convention for the use and care of animals. The study was approved by the Institutional Review Board of the School of Medicine of the University of Sao Paulo.

\section{Study design}

The rats were anesthetized, tracheostomized and mechanically ventilated and randomly assigned to 12 groups ( $\mathrm{n}=6$ for each group). The rats were ventilated with either dry air at $13^{\circ} \mathrm{C}$, dry air at $37^{\circ} \mathrm{C}$, humid air at $13^{\circ} \mathrm{C}$ and humid air at $37^{\circ} \mathrm{C}$. These groups were further divided into three subgroups with a respiratory frequency adjusted to reach a carbon dioxide tension in arterial blood $\left(\mathrm{Pa}, \mathrm{CO}_{2}\right)$ of 30,40 and $50 \mathrm{mmHg}$. Increasing doses of methacholine were infused intravenously, tracheal pressure, airflow and lung volume changes were obtained and respiratory system resistance (Rrs) and elastance (Ers) were calculated.

\section{Methods}

The rats were anaesthetized with pentobarbital sodium $\left(50 \mathrm{mg} \cdot \mathrm{kg}^{-1}\right.$ i.p. $)$. Once surgical-level anaesthesia was achieved, the animals were secured supine, a tracheotomy was created and a polyethylene tube (internal diameter $=1.7 \mathrm{~mm}$ ) was inserted into the trachea. A jugular vein was cannulated to infuse methacholine solutions and a carotid artery was cannulated to drain arterial blood for measurements of $\mathrm{pH}$, oxygen tension in arterial blood $\left(\mathrm{Pa}, \mathrm{O}_{2}\right)$ and $P a, \mathrm{CO}_{2}$, using a Stat Profile 10 (Nova Biomedical Inc., Waltham, MA, USA). Both procedures were performed using a polyethylene tube (internal diameter $=1.1 \mathrm{~mm}$ ) and the arterial line was kept free from blood clotting with heparin solution at $10 \mathrm{U} \cdot \mathrm{mL}^{-1}$.

The animals were ventilated with a small animal ventilator (Harvard 683; Harvard Apparatus, South Natick, MA, USA) with a tidal volume ( $V \mathrm{~T})$ of $10 \mathrm{~mL} \cdot \mathrm{kg}^{-1}$. The respiratory rate was adjusted to achieve the $P a, C_{2}$ previously assigned $(30,40$ or $50 \mathrm{mmHg} \pm 10 \%$ ). The range was $60-90$ breaths $\cdot \mathrm{min}^{-1}$ (table 1). In order to wet the ventilation gas, a bypass system was used where the gas passed under a water column in a vaporization camera, set to 13 or $37^{\circ} \mathrm{C}$. Humidity was measured at the vaporization camera and temperature was monitored just before the entry of the tracheal tube.

Rats were randomly assigned to 12 groups. Animals were ventilated with: 1) dry air (3 parts per million (ppm) of $\mathrm{H}_{2} \mathrm{O}$ ) at $\left.13^{\circ} \mathrm{C}(\mathrm{D} 13) ; 2\right)$ dry air at $37^{\circ} \mathrm{C}$ (D37); 3) humid air (100\% saturation) at $13^{\circ} \mathrm{C}(\mathrm{H} 13)$; 4) humid air at $37^{\circ} \mathrm{C}(\mathrm{H} 37)$. Each one of these groups were further divided into three subgroups that had the frequency of the ventilator adjusted to reach a $P$ a, $C_{2}$ of 30,40 and $50 \mathrm{mmHg}$ ( $\mathrm{n}=6$ for each final group).

Measurements of $R \mathrm{rs}$ and $E \mathrm{rs}$ were performed as previously described [6, 7]. A pneumotachograph (Fleish-4.0; OEM Medical Inc., Richmond, VI, USA) was connected to the tracheal tube and to a differential pressure transducer (Honeywell 163PC01D36; Freeport, IL, USA) to measure airflow $\left(V^{\prime}\right)$. Tracheal pressure $(P \operatorname{tr})$ was measured with a pressure transducer (Honeywell 142PC05D). $V^{\prime}$ and $P$ tr signals were measured and conditioned during $10 \mathrm{~s}$ at $200 \mathrm{~Hz}$ with a 12-bit analog-to-digital converter (DT 01-EZ; Data Translation, Marlboro, MA, USA) and stored in a microcomputer. In each measurement, 10,13 or 15 cycles, according to the

Table 1. - Values of respiratory frequency $(\mathrm{RF})$, carbon dioxide tension in arterial blood $\left(\mathrm{Pa}, \mathrm{CO}_{2}\right)$, oxygen tension in arterial blood $\left(\mathrm{Pa}_{\mathrm{a}} \mathrm{O}_{2}\right)$ and $\mathrm{pH}$ in the 12 groups of rats studied

\begin{tabular}{|c|c|c|c|c|c|c|}
\hline Air type & Temperature & $\begin{array}{c}\text { Set } \mathrm{Pa}_{\mathrm{a}, \mathrm{CO}_{2}} \\
\mathrm{mmHg}\end{array}$ & $\mathrm{RF} \cdot \mathrm{min}^{-1}$ & $P \mathrm{a}, \mathrm{CO}_{2} \mathrm{mmHg}$ & $\mathrm{Pa}_{\mathrm{a}, \mathrm{O}_{2}} \mathrm{mmHg}$ & $\mathrm{PH}$ \\
\hline \multirow[t]{6}{*}{ Dry air } & \multirow[t]{3}{*}{$13^{\circ} \mathrm{C}$} & 30 & $99.97 \pm 5.17 * *$ & $30.68 \pm 1.0 * *$ & $82.55 \pm 5.2$ & $7.43 \pm 0.03$ \\
\hline & & 40 & $82.80 \pm 6.26^{\#}$ & $39.88 \pm 0.7^{\#}$ & $73.25 \pm 3.8$ & $7.36 \pm 0.01^{+}$ \\
\hline & & 50 & $62.83 \pm 6.63$ & $50.30 \pm 1.0$ & $54.12 \pm 4.3^{\natural}$ & $7.27 \pm 0.04$ \\
\hline & \multirow[t]{3}{*}{$37^{\circ} \mathrm{C}$} & 30 & $94.83 \pm 5.72 * *$ & $29.83 \pm 0.83^{* *}$ & $95.83 \pm 10.18$ & $7.39 \pm 0.02$ \\
\hline & & 40 & $89.93 \pm 6.98^{\#}$ & $39.63 \pm 1.0^{\#}$ & $81.07 \pm 7.4$ & $7.34 \pm 0.02^{+}$ \\
\hline & & 50 & $62.50 \pm 3.75$ & $52.07 \pm 1.3$ & $59.83 \pm 1.3^{\circ}$ & $7.24 \pm 0.03$ \\
\hline \multirow[t]{6}{*}{ Humid air } & \multirow[t]{3}{*}{$13^{\circ} \mathrm{C}$} & 30 & $100.33 \pm 2.23^{* *}$ & $30.60 \pm 0.9 * *$ & $74.22 \pm 3.5$ & $7.47 \pm 0.02$ \\
\hline & & 40 & $76.00 \pm 3.49^{\#}$ & $39.62 \pm 0.9^{\#}$ & $70.53 \pm 3.5$ & $7.41 \pm 0.02^{+}$ \\
\hline & & 50 & $66.75 \pm 4.25$ & $50.20 \pm 0.7$ & $51.60 \pm 7.6^{\circ}$ & $7.34 \pm 0.02$ \\
\hline & \multirow[t]{3}{*}{$37^{\circ} \mathrm{C}$} & 30 & $99.75 \pm 3.53 * *$ & $30.85 \pm 0.8 * *$ & $74.90 \pm 5.3$ & $7.48 \pm 0.01$ \\
\hline & & 40 & $88.86 \pm 3.33^{\#}$ & $40.94 \pm 1.1^{\#}$ & $62.63 \pm 5.6$ & $7.41 \pm 0.02^{+}$ \\
\hline & & 50 & $67.00 \pm 3.40$ & $50.26 \pm 1.0$ & $58.62 \pm 3.9^{9}$ & $7.36 \pm 0.02$ \\
\hline
\end{tabular}

Data are presented as mean \pm SEM. ${ }^{* *}: \mathrm{p}<0.001$ compared to groups 40 and $50 ;{ }^{*}: \mathrm{p}<0.001$ compared to group $50 ;{ }^{\bullet}: \mathrm{p}<0.001$ compared to groups 30 and $40 ;{ }^{+}: \mathrm{p}=0.002$ compared to groups 30 and 50 . 
respiratory frequency setup, were analysed for each data point. Lung volume changes $(V)$ were obtained by electronic integration of the $V^{\prime}$ signal.

$R$ rs and $E_{\text {rs }}$ were obtained using the equation of motion of the respiratory system:

$$
P_{\mathrm{tr}}=E_{\mathrm{rs}} \times V(\mathrm{t})+R_{\mathrm{rs}} \times V^{\prime}(\mathrm{t})
$$

where (t) is time. After the rats had achieved the desired $P$ a, $\mathrm{CO}_{2}$, the groups of animals designed to proceed under dry ventilation had their $P \operatorname{tr}$ and $V^{\prime}$ measured (baseline). $V^{\prime}$ was also measured directly after achieving a maximal increase in $P$ tr that followed each intravenous infusion of increasing concentrations of methacholine chloride (Sigma Chemical Co., Saint Louis, MI, USA) in normal saline $\left(0.1-300 \mu \mathrm{g} \cdot \mathrm{kg}^{-1}\right)$. The groups of animals designed to proceed under humid ventilation were kept under those conditions for an additional $10 \mathrm{~min}$. $P \operatorname{tr}$ and $V^{\prime}$ were measured (baseline) and the same protocol of methacholine infusion described earlier was followed. All rats received intermittent deep inflations $(3 \times V \mathrm{~T})$ every 15 min from the start of mechanical ventilation. The last deep inflation was performed immediately before the beginning of methacholine challenge. The methacholine dose/response curve lasted $30 \mathrm{~min}$. The authors previously observed that $30 \mathrm{~min}$ of mechanical ventilation with either dry or humid air and without deep inflations did not change $R$ rs and $E$ rs.

\section{Data analysis}

To compare the dose/response curves to methacholine, the doses of methacholine that caused $50 \%$ of maximal changes in $R$ rs and Ers (termed $\mathrm{Kx} R \mathrm{rs}$ and $\mathrm{Kx} E \mathrm{rs}$, respectively) were calculated for each animal, according to HulberT et al. [8]. The maximal changes in $R \mathrm{rs}$ and $E \mathrm{rs}$ (termed $\Delta \max R \mathrm{rs}$ and $\Delta \max E_{\mathrm{rs}}$, respectively) were calculated. $\mathrm{Kx}$ and $\Delta \max$ values for both $E$ rs and $R$ rs were compared using a three-way analysis of variance (factors $P_{\mathrm{a}}, \mathrm{CO}_{2}$, temperature and humidity) followed by the Tukey Test for multiple comparisons [9].

Baseline values of $R \mathrm{rs}$ and $E \mathrm{rs}$, respiratory frequency, pH, $\mathrm{Pa}, \mathrm{O}_{2}$ and $\mathrm{Pa}_{\mathrm{a}} \mathrm{CO}_{2}$ were also examined using a three-way analysis of variance. A p-value $<0.05$ was considered significant.

\section{Results}

Table 1 shows the respiratory frequency, $P \mathrm{a}, \mathrm{CO}_{2}$, $P \mathrm{a}, \mathrm{O}_{2}$ and $\mathrm{pH}$ (means \pm SEM) values obtained in each of the 12 groups studied. At each set $\mathrm{Pa}_{\mathrm{a}} \mathrm{CO}_{2}$ level $(30,40$ or $50 \mathrm{mmHg}$ ), no significant differences in respiratory frequency, $\mathrm{pH}, \mathrm{Pa}, \mathrm{CO}_{2}$ and $\mathrm{Pa}, \mathrm{O}_{2}$ values were observed when groups D13, D37, H13 and H37 were compared. In the ventilated groups that had lower respiratory frequencies there was a significant decrease in $\mathrm{pH}$ due to higher values of $\mathrm{Pa}, \mathrm{CO}_{2}$ as well as significantly lower values of $\mathrm{Pa}, \mathrm{O}_{2}$, since all animals were ventilated with a concentration of oxygen of $21 \%$ in the inspired air.

Table 2 shows baseline values of $R$ rs and Ers. These values were obtained immediately before the beginning of methacholine challenges. There was no significant influence of temperature or humidity of the inspired air or the level of alveolar ventilation on basal values.

No significant influence of the temperature of inspired air on $\Delta \max$ values for either $R$ rs or $E$ rs was observed (figs. 1 and 2). In contrast, values of $\Delta \max E$ rs in the groups ventilated with humid air were significantly lower than in the groups ventilated with dry air $(\mathrm{p}<0.001)$. Moreover, the decrease in alveolar ventilation resulted in significantly greater values of $\Delta \max E \mathrm{rs}(\mathrm{p}<0.001)$. Statistically significant differences in $\Delta \max R$ rs values were not observed. Finally, there were no differences in $\mathrm{Kx}$ values among the groups studied, for both Ers and Rrs (figs. 3 and 4).

\section{Discussion}

The influence of alveolar ventilation degree, temperature and humidity on pulmonary responsiveness to a bronchoactive agonist has been studied here for the first time in a normal animal. The maximal response to methacholine was significantly reduced in the presence of humid air, particularly in small airways, as suggested by significant differences in elastance but not in resistance. Higher ventilation

Table 2. - Values of respiratory system resistance $(R \mathrm{rs})$ and elastance $(E \mathrm{rs})$ in the 12 groups of rats studied

\begin{tabular}{|c|c|c|c|c|}
\hline Air type & Temperature & Set $P \mathrm{a}, \mathrm{CO}_{2} \mathrm{mmHg}$ & $R \mathrm{rs} \mathrm{cmH}_{2} \mathrm{O} \cdot \mathrm{mL}^{-1} \cdot \mathrm{s}^{-1}$ & $E_{\mathrm{rs}} \mathrm{cmH}_{2} \mathrm{O} \cdot \mathrm{mL}^{-1}$ \\
\hline \multirow[t]{6}{*}{ Dry air } & \multirow[t]{3}{*}{$13^{\circ} \mathrm{C}$} & 30 & $0.134 \pm 0.014$ & $2.80 \pm 0.21$ \\
\hline & & 40 & $0.194 \pm 0.018$ & $2.91 \pm 0.30$ \\
\hline & & 50 & $0.196 \pm 0.025$ & $3.28 \pm 0.36$ \\
\hline & \multirow[t]{3}{*}{$37^{\circ} \mathrm{C}$} & 30 & $0.155 \pm 0.027$ & $2.88 \pm 0.18$ \\
\hline & & 40 & $0.164 \pm 0.009$ & $3.25 \pm 0.23$ \\
\hline & & 50 & $0.173 \pm 0.015$ & $3.58 \pm 0.26$ \\
\hline \multirow[t]{6}{*}{ Humid air } & \multirow[t]{3}{*}{$13^{\circ} \mathrm{C}$} & 30 & $0.205 \pm 0.019$ & $2.95 \pm 0.29$ \\
\hline & & 40 & $0.174 \pm 0.020$ & $3.28 \pm 0.31$ \\
\hline & & 50 & $0.198+0.035$ & $3.42+0.29$ \\
\hline & \multirow{3}{*}{$37^{\circ} \mathrm{C}$} & 30 & $0.211 \pm 0.006$ & $3.17 \pm 0.20$ \\
\hline & & 40 & $0.202 \pm 0.022$ & $3.47 \pm 0.33$ \\
\hline & & 50 & $0.205 \pm 0.019$ & $2.95 \pm 0.29$ \\
\hline
\end{tabular}

Data are expressed as mean \pm SEM. $P$ a, $\mathrm{CO}_{2}$ : carbon dioxide tension in arterial blood. 
a)

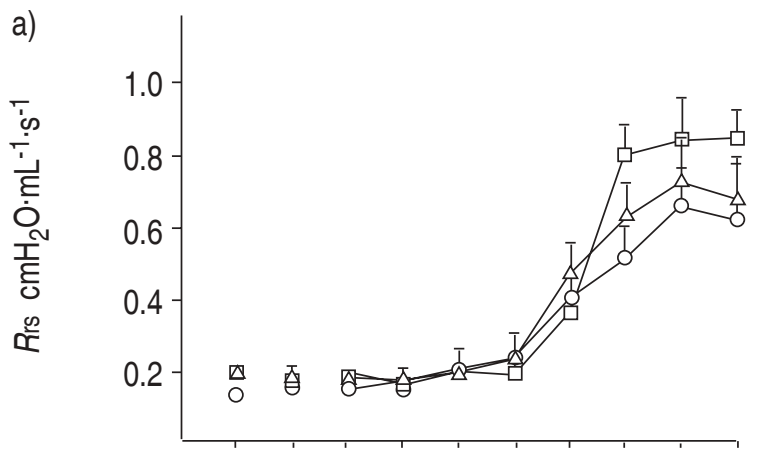

c)

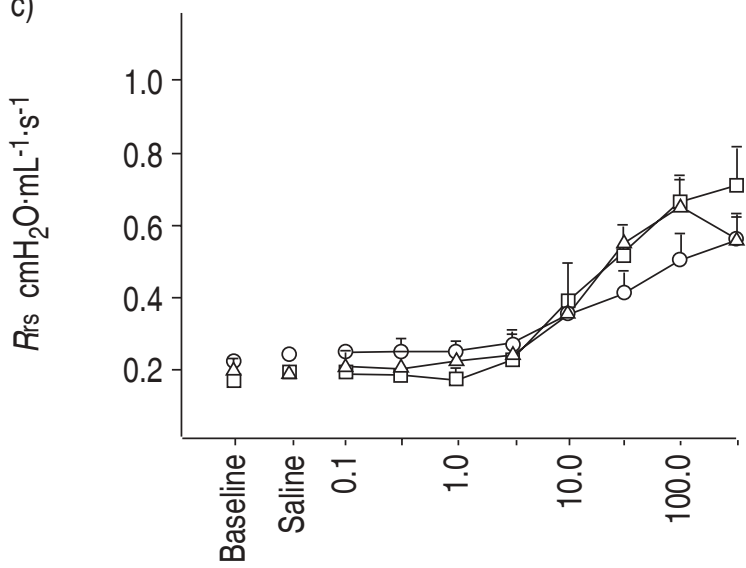

Log concentration of methacholine $\mu \mathrm{g} \cdot \mathrm{kg}^{-1}$ b)

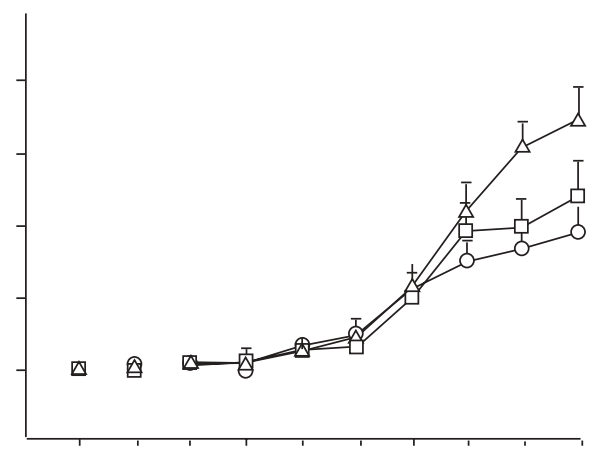

d)

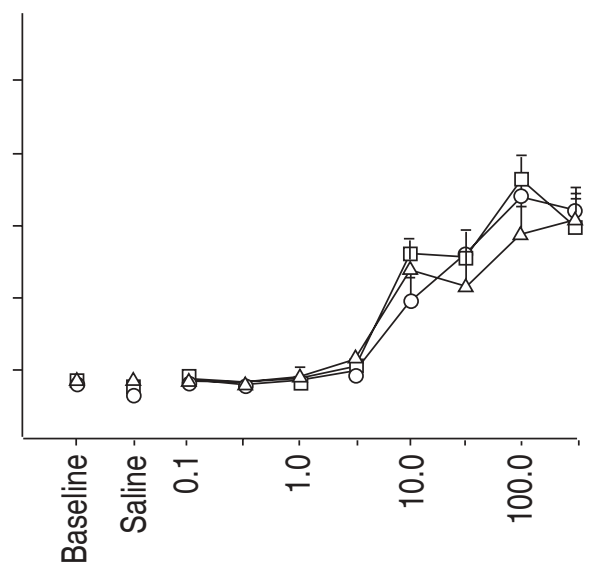

Log concentration of methacholine $\mu \mathrm{g} \cdot \mathrm{kg}^{-1}$

Fig. 1.- Dose/response curves of intravenous methacholine and respiratory system resistance $\left(R_{\mathrm{rs}}\right)$ in rats ventilated with a) dry air at $13^{\circ} \mathrm{C}$, b) dry air at $37^{\circ} \mathrm{C}$, c) humid air at $13^{\circ} \mathrm{C}$ and d) humid air at $37^{\circ} \mathrm{C}$, and with different respiratory frequencies to reach carbon dioxide tension in arterial blood values of $30(\bigcirc), 40(\square)$ or $50(\triangle) \mathrm{mmHg}$. Data are presented as mean \pm SEM.

was also associated with a lower maximal elastance response.

Exercise, hyperventilation and ventilation with cold air cause a transient increase in pulmonary resistance in a substantial number of patients with asthma $(40-90 \%)$ and in some subjects without history of asthma [10-13]. At a fixed level of ventilation, colder and dryer inspired air exacerbates this response. In contrast, ventilation with warmer and more humidified air reduces its severity. There are numerous similarities between exercise- and hyperventilationinduced bronchospasm, such as the time-course of airway narrowing, the degree of evaporative loss of both heat and water and the response to medication $[3,14]$. Because of these similarities, experimental models of hyperventilation have been used to study the mechanisms of exercise-induced bronchospasm $[4,5,14]$. EIB is probably an amplification of the normal response of the airways, since normal subjects show a reduction in forced expiratory volume in one second following high levels of hyperpnoea with cold, dry air [15, 16]. It has been shown that various animal species, such as guinea pigs, dogs, rabbits and monkeys, present airway obstruction in several experimental models of hyperpnoea, mainly those using dry air $[14,17]$. These animal models have been used to study the mechanisms of EIB. However, to the authors' knowledge, previous studies have not investigated the influence of the degree of alveolar ventilation, temperature and humidity on the responsiveness to a bronchoactive agonist, such as methacholine, in a normal animal. These relationships in normal animals are important in experimental situations where there is no change in baseline respiratory mechanics before the infusion of methacholine, as they clarify the influence of temperature, humidity and ventilation on the behaviour of normal airway smooth muscle.

To evaluate the response to methacholine, the dose that caused $50 \%$ of the maximal change in both $E$ rs and $R$ rs was determined as an index of the position of the dose/response curve (sensitivity). The maximal change (reactivity) was also compared [8]. It was observed that temperature, humidity and degree of alveolar ventilation did not significantly influence the position of the curve (fig. 3 and 4). However, the maximal response to i.v. methacholine was significantly affected by ventilation and humidity. These effects were more intense in small airways and/or distal airspaces, as the differences in Ers but not $R$ rs were significant. It has been shown previously that administration of contractile agonists, such as methacholine or acetylcholine, not only results in an increase in airway resistance but also in substantial changes in the mechanical properties of pulmonary parenchyma [18-20]. These observations suggest that 

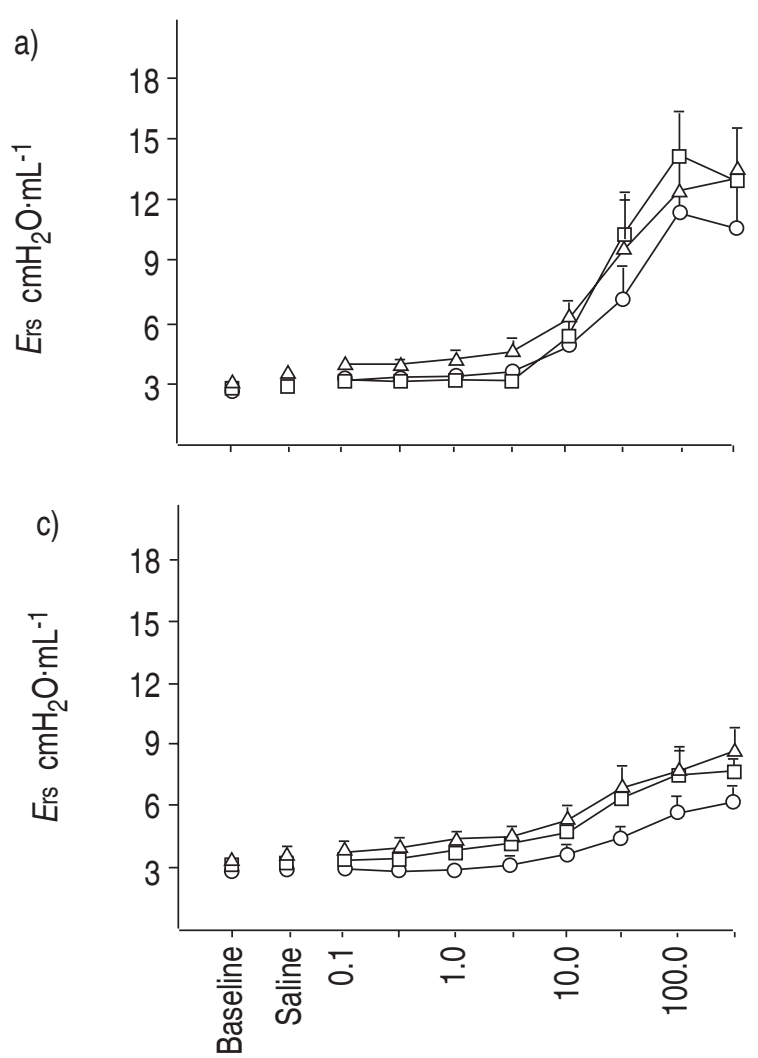

Log concentration of methacholine $\mu \mathrm{g} \cdot \mathrm{kg}^{-1}$ b)

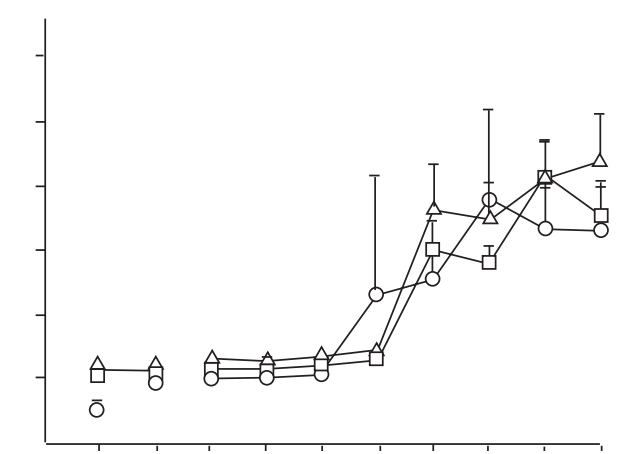

d)

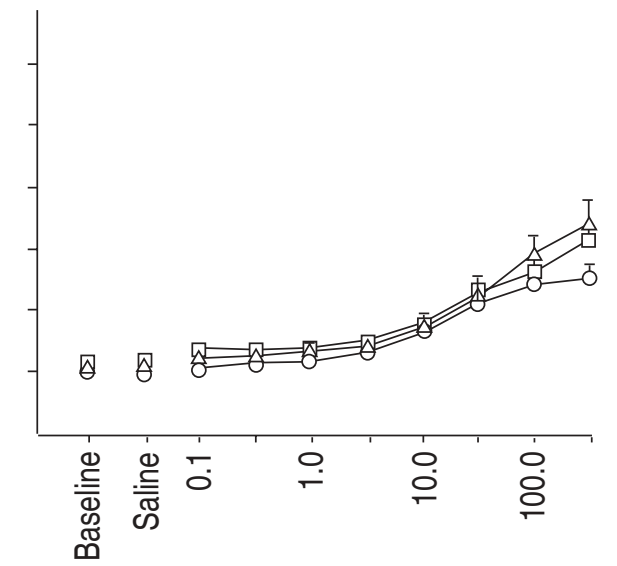

Log concentration of methacholine $\mu \mathrm{g} \cdot \mathrm{kg}^{-1}$

Fig. 2. - Dose/response curves of intravenous methacholine and respiratory system elastance $\left(E_{\mathrm{rs}}\right)$ in rats ventilated with a) dry air at $13^{\circ} \mathrm{C}$, b) dry air at $37^{\circ} \mathrm{C}$, c) humid air at $13^{\circ} \mathrm{C}$ and d) humid air at $37^{\circ} \mathrm{C}$, and with different respiratory frequencies to reach carbon dioxide tension in arterial blood values of $30(\bigcirc), 40(\square)$ or $50(\triangle), \mathrm{mmHg}$. Data are presented as mean \pm SEM.

dryness has a greater effect than low temperature on the pulmonary response to a bronchoconstrictor. Very low temperatures, however, were not used in this study.

A significant influence of the level of alveolar ventilation on the response to methacholine was also observed, with a higher $P \mathrm{a}, \mathrm{CO}_{2}$ associated with a greater maximal response to methacholine. This difference was significant for $E$ rs (fig. 4). This finding is somewhat surprising, since EIB is related to hyperventilation. In contrast with this observation, STEPHENS and Mitchell [21], studying canine isolated tracheal strips, observed a decrease in the isometric maximum tetanic tension in the presence of high $\mathrm{Pa}_{\mathrm{a}} \mathrm{CO}_{2}$. However, StePhens and Mitchell [21] exposed the airway smooth muscle to a much higher $P \mathrm{a}, \mathrm{CO}_{2}$ than in this study $(110$ versus $50 \mathrm{mmHg})$. In addition, it can be speculated that there are differences between the in vitro and in vivo contractile response of airway smooth muscle due to haemodynamic, humoral and/or nervous influences.

The mechanisms of exercise- and hyperventilationinduced bronchospasm are not completely determined, but are thought to be related to the cooling and/or drying of the airways resulting from hyperpnoea. Following these stimuli, airway obstruction is due to mediator release, sensory nerve activation and/ or reactive hyperaemia of the bronchial circulation $[16,22]$. Large as well as small airways are involved in this response $[16,23]$.

In the present study alveolar ventilation was changed by increasing or decreasing respiratory frequency, without modifying $V \mathrm{~T}$ or flow profile of the ventilator, in order to obtain comparable values of $E$ rs and $R$ rs in all groups of rats. With this approach, a group with a lower $P$ a, $\mathrm{CO}_{2}(20 \mathrm{mmHg})$ could not be studied, since the higher respiratory frequency used to reach this value resulted in an increase in baseline tracheal pressure (auto-positive end-expiratory pressure). In addition, if exposed to dry air, rats with higher alveolar ventilation presented higher values of basal (premethacholine) Ers and $R$ rs, perhaps as a result of hyperventilation-induced bronchoconstriction.

Methacholine was infused i.v. to give the same amount of this agonist to all groups of rats. This would not have been possible by aerosol because of the different respiratory frequency of the groups. However, the i.v. infusion of high doses of methacholine has substantial systemic and pulmonary vascular effects, which could theoretically be influenced by $\mathrm{pH}$ or $\mathrm{Pa}, \mathrm{CO}_{2}$.

There are other limitations to this study. Different rodents, such as guinea pigs, rats and mice, and even different strains of rats or mice have shown 

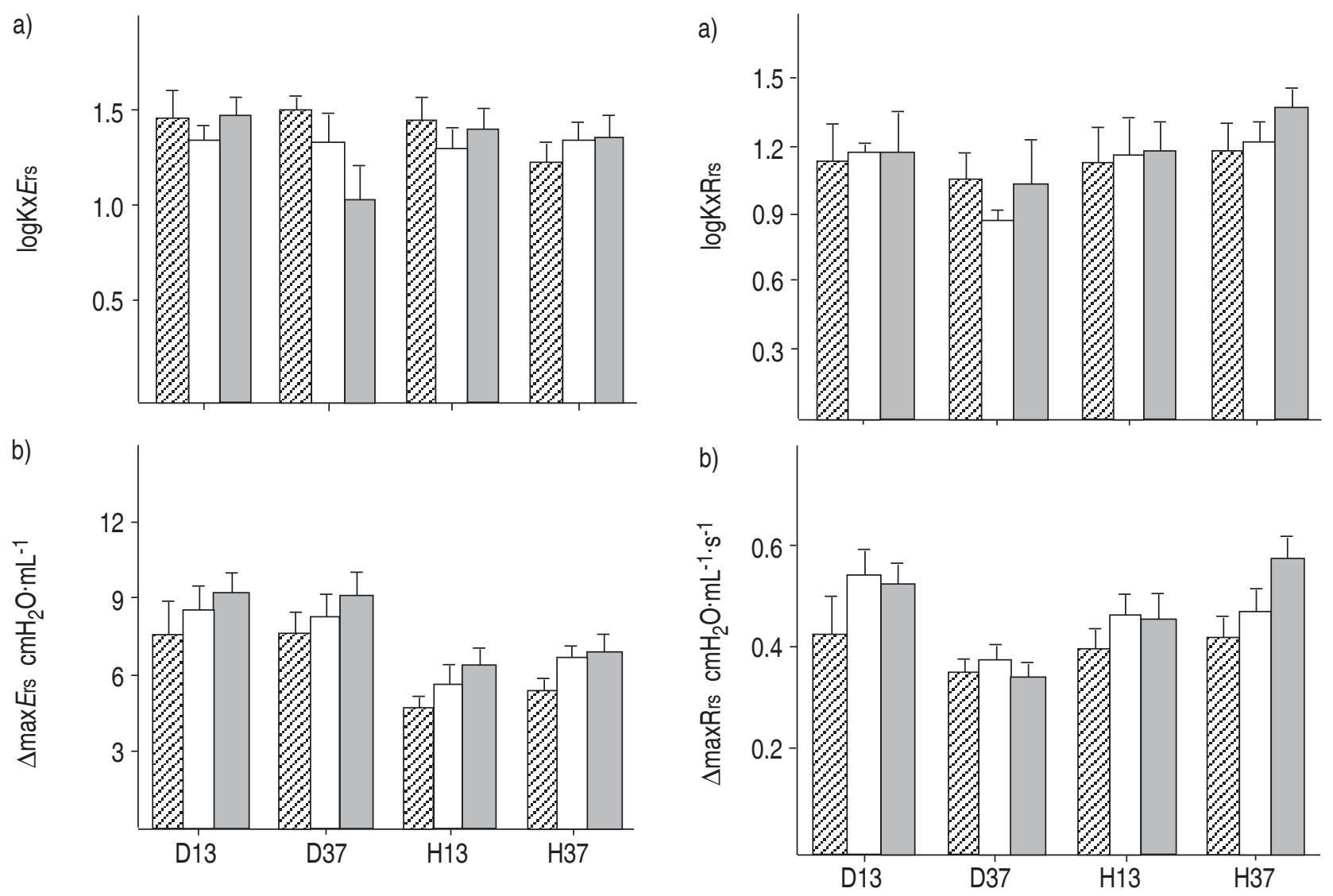

Fig. 3.-a) Values of the logarithm of the dose of intravenous methacholine that caused a $50 \%$ maximal increase in respiratory system elastance $(\log \mathrm{Kx} E \mathrm{rs})$. b) Values of the maximal increase in respiratory elastance $(\Delta \mathrm{max} E \mathrm{rs})$. Animals were ventilated with dry air at $13^{\circ} \mathrm{C}(\mathrm{D} 13)$, dry air at $37^{\circ} \mathrm{C}$ (D37), humid air at $13^{\circ} \mathrm{C}(\mathrm{H} 13)$ and humid air at $37^{\circ} \mathrm{C}(\mathrm{H} 37)$. Data are presented as mean \pm SEM. 『: $30 \mathrm{mmHg} ; \square: 40 \mathrm{mmHg}$; : $50 \mathrm{mmHg}$.

substantially different responses to bronchoactive agonists, such as methacholine. However, only Wistar rats were used in this study. Isocapnic conditions in the lung were not maintained and supplemental oxygen was not administered to the groups of rats that were ventilated with low respiratory frequencies. The rats in the group administered $50 \mathrm{mmHg}$ of $\mathrm{Pa}, \mathrm{CO}_{2}$ had significantly lower values of $\mathrm{Pa}, \mathrm{O}_{2}$, although these values were not low enough to induce substantial changes in pulmonary haemodynamics. The purpose of this study was to reproduce situations of hyperpnoea and hypopnoea, without correction for blood gases. It has been shown previously that carbon dioxide might reduce pulmonary peripheral resistance [24]. However, this was probably not the case in this study, since $\mathrm{Pa}_{\mathrm{a}}, \mathrm{CO}_{2}$ levels did not influence baseline resistance and elastance values.

In conclusion, it has been demonstrated in this study that the pulmonary response to methacholine in normal rats is significantly affected by the humidity of inspired air and the level of alveolar ventilation. Ventilation with dry air and lower respiratory frequency resulted in significantly greater maximal values of respiratory system elastance, but not resistance, suggesting that this effect is more intense

Fig. 4.-a) Values of the logarithm of the dose of intravenous methacholine that caused a $50 \%$ maximal increase in respiratory system resistance $(\log \mathrm{Kx} R \mathrm{rs})$ and of the maximal increase in respiratory resistance $(\Delta \max R \mathrm{rs})$. Animals were ventilated with dry air at $13^{\circ} \mathrm{C}$ (D13), dry air at $37^{\circ} \mathrm{C}$ (D37), humid air at $13^{\circ} \mathrm{C}(\mathrm{H} 13)$ and humid air at $37^{\circ} \mathrm{C}(\mathrm{H} 37)$. Data are presented as mean \pm SEM. $\mathbb{Z}: 30 \mathrm{mmHg}$; $\square: 40 \mathrm{mmHg}$; : $50 \mathrm{mmHg}$.

in the small airways and/or distal airspaces than in larger airways.

Acknowledgements. The authors would like
to thank R.W. Mitchell for his critical review of the manuscript.

\section{References}

1. Barnes PJ. Pharmacology of airway smooth muscle. Am J Respir Crit Care Med 1998; 158: S123-S132.

2. Postma DS, Kerstjens HAM. Characteristics of airway hyperresponsiveness in asthma and chronic obstructive pulmonary disease. Am J Respir Crit Care Med 1998; 158: S187-S192.

3. McFadden ER Jr, Gilbert IA. Exercise-induced asthma. $N$ Engl J Med 1994; 330: 1362-1367.

4. Freed AN, Kelly LJ, Menkes HA. Airflow-induced brochospasm. Imbalance between airway cooling and airway drying? Am Rev Respir Dis 1987; 136: 595-599.

5. Yang XX, Powell WS, Hojo M, Martin JG. Hyperpnea-induced bronchoconstriction is dependent on tachykinin-induced cysteinyl leukotriene synthesis. J Appl Physiol 1997; 82: 538-544. 
6. Warth MPTN, Maldonado EAL, Fernezlian SM, et al. Neurokinin depletion attenuates mechanical and morphological pulmonary changes induced by antigen challenge in sensitized guinea pigs. Am $J$ Physiol (Lung Cell Mol Physiol) 1995; 268: L781-L788.

7. Tiberio IFLC, Turco GMG, Leick-Maldonado EA, et al. Effects of neurokinin depletion on airway inflammation induced by chronic antigen exposure. Am J Respir Crit Care Med 1997; 155: 1739-1747.

8. Hulbert WC, McLean T, Wiggs B, Paré PD, Hogg JC. Histamine dose-response curves in guinea-pigs. $J$ Appl Physiol 1985; 58: 625-634.

9. Zar JH ed. Biostatistical analysis. 2nd Edn. Englewood Cliffs, NJ, USA, Prentice-Hall Inc.; pp. 244-252.

10. Cabral ALB, Conceição GMS, Fonseca CHF, Martins MA. Exercise-induced bronchospasm in children: Effects of asthma severity. Am J Respir Crit Care Med 1999; 159: 1816-1823.

11. Poppius H, Muittari A, Kreus K-E, Korhonen O, Viljanen A. Exercise asthma and disodium cromoglycate. BMJ 1970; 4: 337-339.

12. Jones RS, Buston MH, Wharton MJ. The effect of exercise on ventilatory function in the child with asthma. Br J Dis Chest 1962; 56: 78-86.

13. Kawabori I, Pierson WE, Conquest LL, Bierman $\mathrm{CW}$. Incidence of exercise-induced asthma in children. J Allergy Clin Immunol 1976; 58: 447-455.

14. Freed AN. Models and mechanisms of exerciseinduced asthma. Eur Respir J 1995; 8: 1770-1785.

15. O'Cain CF, Dowling NB, Slutsky AS, et al. Airway effects of respiratory heat loss in normal subjects. J Appl Physiol 1980; 49: 875-880.

16. Kaminsky DA, Irvin CG, Gurka DA, et al. Peripheral airways responsiveness to cool, dry air in normal and asthmatic individuals. Am J Respir Crit Care Med 1995; 152: 1784-1790.

17. Freed AN, Adkinson NF Jr. Dry air-induced late phase responses in the canine lung periphery. Eur Respir J 1990; 3: 434 440.

18. Sakae RS, Martins MA, Criado PMP, Zin WA, Saldiva PHN. In vivo evaluation of airway and pulmonary tissue response to inhaled methacholine in the rat. J Appl Toxicol 1992; 12: 235-238.

19. Salerno FG, Kurosawa H, Eidelman DH, Ludwig MS. Characterization of the anatomical structures involved in the contractile response to the rat lung periphery. Br J Pharmacol 1996; 118: 734-740.

20. Dolnikoff M, Morin J, Ludwig MS. Human lung parenchyma responds to contractile stimulation. Am J Respir Crit Care Med 1998; 158: 1607-1612.

21. Stephens NL, Mitchell RW. Mechanism of action of respiratory acidosis on tracheal smooth muscle. $\mathrm{Am}$ J Physiol 1974; 227: 647-651.

22. Anderson SD, Daviskas E. The airway microvasculature and exercise induced asthma. Thorax 1992; 47: 748-752.

23. Mildon A, Leroux M, Hutcheon M, Zamel N. The site of airways obstruction in exercise-induced asthma. Am Rev Respir Dis 1974; 110: 409-414.

24. Menkes HA, Traystman RJ. Collateral ventilation. Am Rev Respir Dis 1977; 116: 287-309. 